\title{
N-Arylation of Protected and Unprotected 5-Bromo-2-aminobenzimidazole as Organic Material: Non-Linear Optical (NLO) Properties and Structural Feature Determination through Computational Approach
}

\author{
Mubeen Mumtaz ${ }^{1}$, Nasir Rasool ${ }^{1, *}$, Gulraiz Ahmad ${ }^{1}\left(\mathbb{D}\right.$, Naveen Kosar ${ }^{2,3}$ and Umer Rashid $^{4, *(D)}$ \\ 1 Department of Chemistry, Government College University, Faisalabad 38000, Pakistan; \\ advomubeen@ymail.com (M.M.); gulchemist35@gmail.com (G.A.) \\ 2 Department of Chemistry, University of Management and Technology (UMT), C11, Johar Town, \\ Lahore 54770, Pakistan; naveen.kosar@umt.edu.pk \\ 3 Department of Chemistry, COMSATS University Islamabad, Abbottabad Campus, \\ Abbottabad 22060, Pakistan \\ 4 Institute of Nanoscience and Nanotechnology (ION2), Universiti Putra Malaysia (UPM), \\ Serdang 43400, Selangor, Malaysia \\ * Correspondence: nasirrasool@gcuf.edu.pk (N.R.); umer.rashid@upm.edu.my (U.R.)
}

check for updates

Citation: Mumtaz, M.; Rasool, N.; Ahmad, G.; Kosar, N.; Rashid, U. N-Arylation of Protected and Unprotected

5-Bromo-2-aminobenzimidazole as Organic Material: Non-Linear Optical (NLO) Properties and Structural Feature Determination through Computational Approach. Molecules 2021, 26, 6920. https://doi.org/ $10.3390 /$ molecules 26226920

Academic Editor: Alexander V. Aksenov

Received: 2 July 2021

Accepted: 20 October 2021

Published: 17 November 2021

Publisher's Note: MDPI stays neutral with regard to jurisdictional claims in published maps and institutional affiliations.

Copyright: (c) 2021 by the authors. Licensee MDPI, Basel, Switzerland. This article is an open access article distributed under the terms and conditions of the Creative Commons Attribution (CC BY) license (https:/ / creativecommons.org/licenses/by/ $4.0 /)$.

\begin{abstract}
The interest in the NLO response of organic compounds is growing rapidly, due to the ease of synthesis, availability, and low loss. Here, in this study, $\mathrm{Cu}$ (II)-catalyzed selective $\mathrm{N}$-arylation of 2-aminobenzimidazoles derivatives were achieved in the presence of different bases $\mathrm{Et}_{3} \mathrm{~N} / \mathrm{TMEDA}$, solvents $\mathrm{DCM} / \mathrm{MeOH} / \mathrm{H}_{2} \mathrm{O}$, and various aryl boronic acids under open atmospheric conditions. Two different copper-catalyzed pathways were selected for $\mathrm{N}$-arylation in the presence of active nucleophilic sites, providing a unique tool for the preparation of NLO materials, C-NH (aryl) derivatives of 2-aminobenzimidazoles with protection and without protection of $\mathrm{NH}_{2}$ group. In addition to NMR analysis, all synthesized derivatives (1a-1f and 2a-2f) of 5-bromo-2-aminobenzimidazole (1) were computed for their non-linear optical (NLO) properties and reactivity descriptor parameters. Frontier molecular orbital (FMO) analysis was performed to get information about the electronic properties and reactivity of synthesized compounds.
\end{abstract}

Keywords: benzimidazole; N-arylation; optimization; FMOs analysis; non-linear optical properties

\section{Introduction}

There are 30 derivatives of 2-aminobenzimidazole registered in the world as drugs that exhibit diverse pharmacological activities, e.g., antiparasitic, antifungal, antiviral, and antiallergic [1]. The 2-aminobenzimidazoles are interesting compounds with many biological effects, such as immunotropic, diuretic, antihistamine, and highly selective characteristics of p38aMaP inhibition [2-4]. Moreover, 2-aminobenzimidazole derivatives with antiviral activity against herpes simplex virus (HSV), human cyclomegalo virus (HCMV), and HIV have also been developed and patented [5-7]. The benzimidazole moiety is also a component of chemosensor receptors, which are utilized to recognize anions selectively and play an essential part in several biological activities [8]. The polyfunctionality of the cyclic guanidine moiety in the 2-aminobenzimidazole has made it a building block for the synthesis of a wide range of pharmacologically important benzimidazole derivatives $[9,10]$. Therefore, the selective N-arylation of amino-substituted N-heterocycles without protection and with protection of nucleophilic sites is important synthetically, as it gives an easy approach to a variety of different bio-actively potent $\mathrm{N}$-arylated compounds.

Optimizing a catalytic pathway for substrates, where a couple of hetero atom sites are available for cross-coupling reactions, is an actual challenge for the organic chemist. The 
selective $\mathrm{N}$-arylation of heteroaromatics, which has more than one nucleophilic site, could be precious because it quickly develops molecular complexity in target molecules with the fewest synthetic influences. However, a large number of transition metal-catalyzed protocols have developed as incredible tools for numerous types of regio/chemoselective $\mathrm{N}$-(hetero) arylation reactions in organic synthesis [11]. Different Pd- and Cu-catalyzed arylations, such as Goldberg [12], Ullman [13], and Buchwald-Hartwig [14] procedures, were used for $\mathrm{N}$-arylations of azoles. More recently, the copper-catalyzed Chan-Lam coupling method for arylation of N-nucleophile by using copper acetate and aryl boronic acids was introduced as the standard because of its mild reaction conditions $[15,16]$. The Chan-Lam coupling has been used for $\mathrm{N}$-arylation of various amines, anilines, esters, imidazoles, and nitrogen-containing heterocycles [17].

These days computational chemistry [18] has emerged as a well-recognized partner of experimental chemistry. Computational chemistry is an extremely vast topic but herein we limited ourselves to density functional theory (DFT) [19]. Over the last 40 years, density functional theory (DFT) has become the most dominant and powerful tool in computational quantum chemistry for the modeling and simulation of chemical systems. Materials demonstrating great non-linear optical response play a key role in telecommunication, optical information processing, optical computing, etc. [20,21]. Nadeem and co-workers studied benzimidazole derivatives to tune the second-order nonlinear optical molecular switching by proton abstraction. Their results illustrate that substituted compounds have robustly large off-on NLO switching with a difference in $\beta_{0}$ values of $7,63,85$, and 75 times larger than their neutral counterparts, respectively [22]. Tayade and Sekar examined Benzimidazole-Thiazole based NLOphoric Styryl Dyes both experimentally and theoretically. The nonlinear response based on $\alpha$, and $\beta$ was increased after the substitution of acceptor groups [23]. Thakare et al. experimentally and theoretically analyzed the NLO response of BODIPY-benzimidazole conjugate. The results obtained from the DFT method are in good accordance with those produced from solvatochromic method. The values obtained for nonlinear absorption coefficient $(\beta)$ and third-order susceptibility $\chi(3)$ are $7.45 \times 10^{12}$ and $3.85 \times 10^{13}$, respectively [24]. These reports shed light on the importance of substituted benzimidazole synthesis and their use in the field of optical and nonlinear optical materials using the DFT method.

In the present study, 2-aminobenzimidazole and its derivatives were synthesized via Chan-Lam cross-coupling reaction and analyzed theoretically for structural, spectroscopic [25], and NLO properties [26]. Density functional theory (DFT) calculations were used to investigate quantum chemical parameters, such as electron affinity $\left(E_{A}\right)$, ionization potential $(I)$, electronic chemical potential $(\mu)$, electrophilicity index $(\omega)$, and chemical hardness $(\eta)$ [27] of synthesized derivatives of 5-bromo-2-aminobenzimidazole. We hope that electron-donating and withdrawing groups substitution can enhance the NLO response of the newly designed bezimidazoles, and we will obtain large first-order hyperpolarizability for these compounds.

\section{Results and Discussion}

\subsection{Chemistry}

For the acquisition of optimized protocol for selective C-NH arylation of 5-bromo-2aminobenzimidazole, we initiated our examination by adopting two different protocols in which we used 5-bromo-2-aminobenzimidazole (1) and its derivative $\mathrm{N}$-(5-bromo- $1 \mathrm{H}$ benzo[ $d]$ imidazol-2-yl)acetamide (2) with aryl boronic acids in presence of $\mathrm{Cu}(\mathrm{OAc})_{2}$ as a catalyst, Triethylamine $\left(\mathrm{Et}_{3} \mathrm{~N}\right)$ or Tetramethylethylenediamine (TMEDA) as a base, and the solvent DCM and methanol. The reaction was carried out at normal temperature under an open-air environment (Scheme 1).

$\mathrm{N}$-(5-bromo-1H-benzo[d]imidazol-2-yl)acetamide (2) was synthesized after selective protection of amino group of 5-bromo-2-aminobenzimidazole (1) by acetic anhydride at $40{ }^{\circ} \mathrm{C}$ through a previously reported method [28]. 
<smiles>Nc1nc2cc(Br)ccc2[nH]1</smiles><smiles>[R]c1ccc(-n2c(N)nc3cc(Br)ccc32)cc1C#[Y]Cc1ccc(B(O)O)cc1</smiles><smiles>CC(=O)Nc1nc2cc(Br)ccc2[nH]1</smiles>

2<smiles>[R]c1ccc(-n2c(NC(C)=O)nc3cc(Br)ccc32)cc1[Y]([Y])([H])c1ccc(B(O)O)cc1</smiles>

Scheme 1. Synthesis of and 5-bromo-1H-benzo[d]imidazol-2-amine derivatives (1a-1f), $N$-(5-bromo- $1 H$-benzo[d]imidazol2-yl)acetamide (2), and $N$-(5-bromo- $1 H$-benzo[ $d$ ]imidazol-2-yl)acetamide derivatives (2a-2f). Reagents and conditions: (1) $\mathrm{Cu}(\mathrm{OAc})_{2}(0.94 \mathrm{mmol}), \mathbf{1}(0.94 \mathrm{mmol})$, Arylboronic acid $(1.88 \mathrm{mmol}), \mathrm{Et}_{3} \mathrm{~N} / \mathrm{TMEDA}(1.88 \mathrm{mmol}), \mathrm{MeOH} / \mathrm{H}_{2} \mathrm{O}(8: 1)$, r.t., air, time of $2 \mathrm{~h}$; (2) 1 (47 mmol), acetic anhydride (5 mL), temperature of $40{ }^{\circ} \mathrm{C}$, time of $4 \mathrm{~h}$; (3) $\mathrm{Cu}(\mathrm{OAc})_{2}(0.59 \mathrm{mmol})$, $2(0.39 \mathrm{mmol})$, Arylboronic acid $(0.47 \mathrm{mmol}), \mathrm{Et}_{3} \mathrm{~N} / \mathrm{Py}(0.59 \mathrm{mmol}), \mathrm{DCM}(10 \mathrm{~mL})$, r.t., air, time of $24-72 \mathrm{~h}$.

Generally, N-arylation of the heterocyclic compound with aryl boronic acid takes place under anhydrous conditions. In one protocol of direct N-arylation of 5-bromo-2aminobenzimidazole (1) to produce its derivatives 1a-1f (Figure 1), we used a TMEDA base and $\mathrm{Cu}(\mathrm{OAc})_{2} \cdot \mathrm{H}_{2} \mathrm{O}$ catalyst with mixed parotic solvent $\left(\mathrm{CH}_{3} \mathrm{OH} / \mathrm{H}_{2} \mathrm{O}\right.$ 8:1). The desired products were obtained in good yield within only $2 \mathrm{~h} \mathrm{[29].} \mathrm{In} \mathrm{contrast,} \mathrm{in} \mathrm{the} \mathrm{second}$ protocol for selective $\mathrm{N}$-arylation of $\mathrm{N}$-(5-bromo- $1 \mathrm{H}$-benzo[d]imidazol-2-yl)acetamide (2) to produce its derivatives $\mathbf{2 a - 2 f}$ (Figure 2), we used anhydrous $\mathrm{Cu}(\mathrm{OAc})_{2}$ instead of $\mathrm{Cu}(\mathrm{OAc})_{2} \cdot \mathrm{H}_{2} \mathrm{O}$ with aryl boronic acid in presence of dry DCM instead of $\mathrm{CH}_{3} \mathrm{OH} / \mathrm{H}_{2} \mathrm{O}$, $\mathrm{Et}_{3} \mathrm{~N}$, and $4 \AA$ molecular sieves $[15,30]$. This method was not found efficient, as we failed to isolate the desired product in good yield, even after $24 \mathrm{~h}$, and various tedious steps, such as protection of 5-bromo-2-aminobenzimidazole (1) involved in this method. It was noticed that, by the addition of TMEDA base and a small amount of water, the yield of desired products is enhanced significantly.<smiles>Cc1ccc(-n2c(N)nc3cc(Br)ccc32)cc1</smiles><smiles>Nc1nc2cc(Br)ccc2n1-c1cccnc1</smiles>
$1 d$<smiles>COc1ccc(-n2c(N)nc3cc(Br)ccc32)cc1</smiles><smiles>Cc1cc(C)cc(-n2c(N)nc3cc(Br)ccc32)c1</smiles><smiles>Nc1nc2cc(Br)ccc2n1-c1cccc(Cl)c1</smiles>

1c<smiles>Nc1nc2cc(Br)ccc2n1-c1ccsc1</smiles>

$1 f$

Figure 1. Synthesized 5-bromo-1H-benzo[d]imidazol-2-amine derivatives (1a-1f). 
<smiles>CC(=O)Nc1nc2cc(Br)ccc2n1-c1ccc(C)cc1</smiles>

$2 a$<smiles>CC(=O)Nc1nc2cc(Br)ccc2n1-c1cccnc1</smiles>

2d<smiles>COc1ccc(-n2c(NC(C)=O)nc3cc(Br)ccc32)cc1</smiles>

$2 b$<smiles>CC(=O)Nc1nc2cc(Br)ccc2n1-c1cc(C)cc(C)c1</smiles>

$2 \mathrm{e}$<smiles>CC(=O)Nc1nc2cc(Br)ccc2n1-c1cccc(Cl)c1</smiles>

2c<smiles>CC(=O)Nc1nc2cc(Br)ccc2n1-c1ccsc1</smiles>

$2 f$

Figure 2. Synthesized $N$-(5-bromo-1H-benzo[d]imidazol-2-yl)acetamide derivatives (2a-2f).Different aryl/heteroaryl boronic acids were used in Suzuki Cross-coupling reactions under optimized conditions to get the desired derivatives of 5-bromo-2-aminobenzimidazole (1). The \%age yield of various synthesized derivatives $\mathbf{1 a - 1 f}$ and $\mathbf{2 a - 2} \mathbf{f}$ are given in Tables 1 and 2.

Table 1. Optimization of $\mathrm{Cu}(\mathrm{II})$-catalyzed C-N cross-coupling of 5-bromo-2-aminobenzimidazole and aryl boronic acid in $\mathrm{MeOH} / \mathrm{H}_{2} \mathrm{O}$ at room temperature.

\begin{tabular}{ccccc}
\hline Entry & Aryl Boronic Acid & Base & Product & Yield (\%) \\
\hline $\mathbf{1}$ & $4-\mathrm{MeC}_{6} \mathrm{H}_{4} \mathrm{~B}(\mathrm{OH})_{2}$ & $\mathrm{Et}_{3} \mathrm{~N}$ & $\mathbf{1 a}$ & trace \\
$\mathbf{2}$ & $4-\mathrm{MeC}_{6} \mathrm{H}_{4} \mathrm{~B}(\mathrm{OH})_{2}$ & TMEDA & $\mathbf{1 a}$ & 70 \\
$\mathbf{3}$ & $4-\mathrm{MeC}_{6} \mathrm{H}_{4} \mathrm{~B}(\mathrm{OH})_{2}$ & TMEDA & $\mathbf{1 b}$ & 80 \\
$\mathbf{4}$ & $3-\mathrm{ClC}_{6} \mathrm{H}_{4} \mathrm{~B}(\mathrm{OH})_{2}$ & TMEDA & $\mathbf{1 c}$ & 78 \\
$\mathbf{5}$ & $3-\mathrm{NC}_{5} \mathrm{H}_{4} \mathrm{~B}(\mathrm{OH})_{2}$ & TMEDA & $\mathbf{1 d}$ & 73 \\
$\mathbf{6}$ & $3,5-\mathrm{Me}_{2} \mathrm{C}_{6} \mathrm{H}_{3} \mathrm{~B}(\mathrm{OH})_{2}$ & TMEDA & $\mathbf{1 e}$ & 71 \\
$\mathbf{7}$ & $3-\mathrm{SC}_{4} \mathrm{H}_{3} \mathrm{~B}(\mathrm{OH})_{2}$ & TMEDA & $\mathbf{1 f}$ & 69 \\
\hline
\end{tabular}

Table 2. Optimization of $\mathrm{Cu}(\mathrm{II})$-catalyzed C-N cross-coupling of 5-bromo- $1 H$-benzo[ $d$ ]imidazol-2amine and aryl boronic acid in DCM at room temperature.

\begin{tabular}{ccccc}
\hline Entry & Aryl Boronic Acid & Base & Product & Yield (\%) \\
\hline $\mathbf{1}$ & $4-\mathrm{MeC}_{6} \mathrm{H}_{4} \mathrm{~B}(\mathrm{OH})_{2}$ & $\mathrm{Et}_{3} \mathrm{~N}$ & $\mathbf{2 a}$ & 40 \\
$\mathbf{2}$ & $4-\mathrm{MeC}_{6} \mathrm{H}_{4} \mathrm{~B}(\mathrm{OH})_{2}$ & $\mathrm{Pyridine}_{2}$ & $\mathbf{2 a}$ & 37 \\
$\mathbf{3}$ & $4-\mathrm{MeC}_{6} \mathrm{H}_{4} \mathrm{~B}(\mathrm{OH})_{2}$ & $\mathrm{Et}_{3} \mathrm{~N}$ & $\mathbf{2 b}$ & 42 \\
$\mathbf{4}$ & $3-\mathrm{ClC}_{6} \mathrm{H}_{4} \mathrm{~B}(\mathrm{OH})_{2}$ & $\mathrm{Et}_{3} \mathrm{~N}$ & $\mathbf{2 c}$ & 41 \\
$\mathbf{5}$ & $3-\mathrm{NC}_{5} \mathrm{H}_{4} \mathrm{~B}(\mathrm{OH})_{2}$ & $\mathrm{Et}_{3} \mathrm{~N}$ & $\mathbf{2 d}$ & 45 \\
$\mathbf{6}$ & $3,5-\mathrm{Me}_{2} \mathrm{C}_{6} \mathrm{H}_{3} \mathrm{~B}(\mathrm{OH})_{2}$ & $\mathrm{Et}_{3} \mathrm{~N}$ & $\mathbf{2 e}$ & 49 \\
$\mathbf{7}$ & $3-\mathrm{SC}_{4} \mathrm{H}_{3} \mathrm{~B}(\mathrm{OH})_{2}$ & $\mathrm{Et}_{3} \mathrm{~N}$ & $\mathbf{2 f}$ & 39 \\
\hline
\end{tabular}

In the present study, it was observed that the base can significantly affect the ChanLam coupling. Et ${ }_{3} \mathrm{~N}$ and pyridine are commonly used bases in Chan-Lam cross-coupling reactions. These bases contain amine additives which donate the electron pair to $\mathrm{Cu}(\mathrm{II})$ and allow it to oxidize $\mathrm{Cu}(\mathrm{III})$ intermediate and also capture the acetic acid which produces during the transmetallation step. For selective $\mathrm{N}$-arylation of 5-bromo-2-aminobenzimidazole (1) without protection, we used TMEDA and $\mathrm{Et}_{3} \mathrm{~N}$ as bases and obtained products in good yield with TMEDA base. It is observed that TMEDA act as a bidentate ligand and forms a more stable complex with copper which enhances its reactivity toward the NH group of imidazole ring as compared to $\mathrm{Et}_{3} \mathrm{~N}$ for its selective $\mathrm{N}$-arylation $[31,32]$. 


\subsection{Density Functional Theory (DFT) Studies}

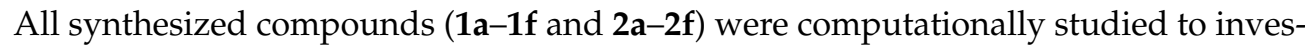
tigate the structural-properties relationships. First of all, compounds were optimized at B3LYP functional of DFT by using GAUSSIAN 09 software [33]. For molecular orbitals description, Pople'6-31+G(d,p) [34] was used (Figure 3A,B). Frequency analysis were completed at the same level of theory for further confirmation of these structures as true minima energy structures on potential energy surfaces. A frontier molecular orbitals (FMOs) analysis and reactivity descriptor parameters were calculated at B3LYP/6-31+G(d,p) method [35]. Nonlinear optical (NLO) properties along with polarizabilities and first hyperpolarizability parameters were evaluated using CAM-B3LYP [36], LC-BLYP [37], and wB97XD [38] density functionals with $6-31+G(d, p)$ basis set.
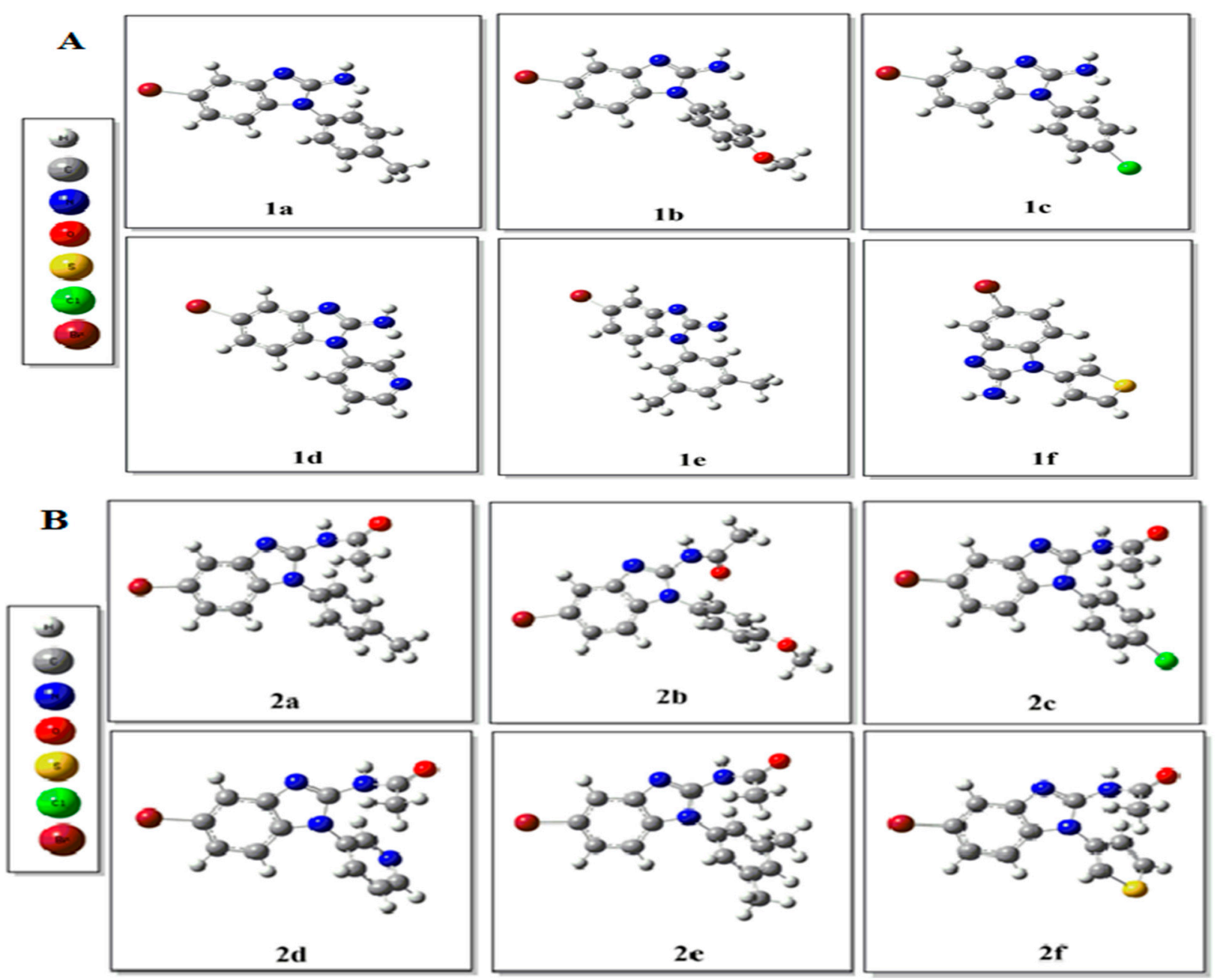

Figure 3. Optimized structures of (A) 1a-1f; (B) 2a-2f at B3LYP/6-31+G(d,p) level of theory.

\subsubsection{Frontier Molecular Orbital (FMO) Analysis}

FMOs analysis is performed to get information about the electronic properties and reactivity of compounds. The energies of HOMOs ( $\mathrm{E}_{\mathrm{HOMO}}$ ) and LUMOs ( $\mathrm{E}_{\mathrm{LUMO}}$ ) explain electronic properties and HOMO-LUMO gaps $\left(\mathrm{G}_{\mathrm{H}-\mathrm{L}}\right)$ validate kinetic stability and reactivity of compounds. Large $\mathrm{G}_{\mathrm{H}-\mathrm{L}}$ declared the less reactivity and more stability of compound and vice versa [39]. The energies of HOMOs ( $\left.\mathrm{E}_{\mathrm{HOMO}}\right)$, energies of LUMOs, $\left(\mathrm{E}_{\mathrm{LUMO}}\right)$, and HOMO-LUMO energy gaps $\left(\mathrm{G}_{\mathrm{H}-\mathrm{L}}\right)$ of all compounds are summarized in Table 3. 
Table 3. Energy of HOMOs ( $\left.\mathrm{E}_{\mathrm{HOMO}}\right)$ and LUMOs ( $\left.\mathrm{E}_{\mathrm{LUMO}}\right)$, HOMO-LUMO energy gap $\left(\mathrm{G}_{\mathrm{H}-\mathrm{L}}\right)$, dipole moment $\left(\mu_{\mathrm{o}}\right)$, polarizability $\left(\alpha_{o}\right)$, and first static hyperpolarizability $\left(\beta_{\mathrm{o}}\right)$ of compounds $\mathbf{1 a}-\mathbf{1 f}$ and $\mathbf{2 a}-\mathbf{2} \mathbf{f}$.

\begin{tabular}{|c|c|c|c|c|c|c|}
\hline Compounds & $\mathrm{E}_{\text {HOMо }}(\mathrm{eV})$ & $\mathrm{E}_{\text {LUMO }}(\mathrm{eV})$ & $\mathrm{G}_{\mathrm{H}-\mathrm{L}}(\mathrm{eV})$ & $\mu_{\mathrm{o} \text { (Debye) }}$ & $\alpha_{\mathrm{o}}(\mathrm{Au})$ & $\beta_{\mathrm{o}}(\mathrm{Esu})$ \\
\hline Density Functionals & \multicolumn{4}{|c|}{ B3LYP } & \multicolumn{2}{|c|}{ CAM-B3LYP } \\
\hline $1 \mathrm{a}$ & -5.81 & -1.12 & 4.69 & 8.46 & 228 & $4.61 \times 10^{-30}$ \\
\hline $1 b$ & -5.78 & -1.11 & 4.66 & 7.95 & 215 & $5.66 \times 10^{-30}$ \\
\hline 1c & -5.99 & -1.50 & 4.49 & 4.91 & 210 & $3.81 \times 10^{-30}$ \\
\hline 1d & -6.02 & -1.77 & 4.25 & 5.63 & 190 & $4.40 \times 10^{-30}$ \\
\hline 1e & -5.79 & -1.10 & 4.69 & 7.56 & 222 & $4.00 \times 10^{-30}$ \\
\hline 1f & -5.91 & -1.39 & 4.52 & 6.32 & 188 & $4.30 \times 10^{-30}$ \\
\hline $2 a$ & -6.44 & -1.40 & 5.04 & 6.05 & 235 & $2.02 \times 10^{-30}$ \\
\hline $2 b$ & -6.19 & -1.11 & 5.08 & 5.93 & 240 & $3.54 \times 10^{-30}$ \\
\hline $2 c$ & -6.59 & -1.68 & 4.91 & 3.74 & 236 & $2.00 \times 10^{-30}$ \\
\hline $2 d$ & -6.66 & -1.87 & 4.79 & 5.35 & 215 & $2.40 \times 10^{-30}$ \\
\hline $2 e$ & -6.42 & -1.39 & 5.03 & 6.03 & 247 & $2.01 \times 10^{-30}$ \\
\hline $2 f$ & -6.52 & -1.52 & 5.00 & 4.69 & 215 & $2.37 \times 10^{-30}$ \\
\hline
\end{tabular}

Among the compounds 1a-1f, 1d has the smallest $\mathrm{G}_{\mathrm{H}-\mathrm{L}}(4.25 \mathrm{eV})$, whose $\mathrm{E}_{\mathrm{HOMO}}$ and $\mathrm{E}_{\mathrm{LUMO}}$ are -6.02 and $-1.77 \mathrm{eV}$, respectively. Thus, $\mathbf{1 d}$ is considered as kinetically less stable and moderately reactive among $\mathbf{1 a}-\mathbf{1 f}$ series. Previously reported gaps for substituted benzimidazole-, thiazole-, and benzothiazole-based compounds range from 3 to $0.63 \mathrm{eV}$. They are reported as highly stable compounds $[23,40,41]$. On the other side, $4.69 \mathrm{eV}$ of $\mathrm{G}_{\mathrm{H}-\mathrm{L}}$ is calculated for compounds $\mathbf{1 a}, \mathbf{1} \mathbf{b}$ and $\mathbf{1 e}$, which represent more stability and less reactivity of these compounds. The other compounds have $\mathrm{G}_{\mathrm{H}-\mathrm{L}}$ values of 4.25 to $4.52 \mathrm{eV}$, which represent their adequate stability with moderate reactivity. In the other series (2a-2f), $\mathbf{2 d}$ has the lower $\mathrm{G}_{\mathrm{H}-\mathrm{L}}(4.79 \mathrm{eV})$, similar to the results of compound $\mathbf{1 d}$. The rest of the compounds have $\mathrm{G}_{\mathrm{H}-\mathrm{L}}$ values from 4.91 to $5.08 \mathrm{eV}$ and represent high stability and less reactivity of these compounds. All compounds of this series have a larger $\mathrm{G}_{\mathrm{H}-\mathrm{L}}$ and are ultimately less reactive compared to compounds 1a-1f (Table 3).

The FMOs isodensity distributions of compounds 1a-1f are shown in Figure 4A. The isodensity in HOMOs is distributed on benzimidazole rings and bromine atoms attached to these rings in compounds 1a and 1e. Bromine is a strong electron-withdrawing group so electronic densities move toward it. However, some of the isodensity also reside on oxygen, chlorine, nitrogen, and sulfur atoms of compounds $\mathbf{1} \mathbf{b}-\mathbf{d}$ and $\mathbf{1 f}$, respectively, because these atoms also have more electronegativity like bromine atoms. The result is the shift of electronic density from benzimidazole rings towards heteroatoms $(\mathrm{C}, \mathrm{O}, \mathrm{N}, \mathrm{S}$, and $\mathrm{Cl})$ attached as substituents. This specific distribution explains the lower HOMO-LUMO gaps of these

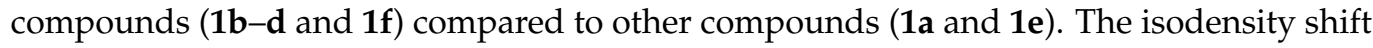
is prominent for $\mathbf{1 d}$ compared to other compounds. The isodensity in LUMOs is mainly distributed on phenyl rings in all compounds (1a-1f, except $\mathbf{1 d})$. These results clarify that the electron densities are migrating mainly from the donor (electron-donating groups terminal) to the acceptor unit (electron-withdrawing groups terminal). Compounds (2a-2f) also have similar isodensity distributions and their HOMO and LUMO densities are given in Figure 4B. Isodenisties are localized on the benzimidazole rings in compounds $\mathbf{2 a}-\mathbf{d}$ and 2e. LUMO densities are present on the aromatic rings. In compounds $2 \mathbf{c}$ and $\mathbf{2 f}, \mathrm{HOMO}$ densities shifted towards the chloro-substituted aromatic and thiophene rings and LUMO densities are on the benzimidazole rings. The gaps are mainly due to the smaller values of the LUMOs of $\mathbf{1 d}$ and $\mathbf{2 d}$, and since the LUMOs are mainly centered on the N-arylated part, the gap is smaller due to the accepting nature of the pyridine. As shown by its highest electrophilicity value, the $\omega$ values of $\mathbf{1 d}$ and $\mathbf{2 d}$ are 3.56 and $3.80 \mathrm{eV}$, respectively. 

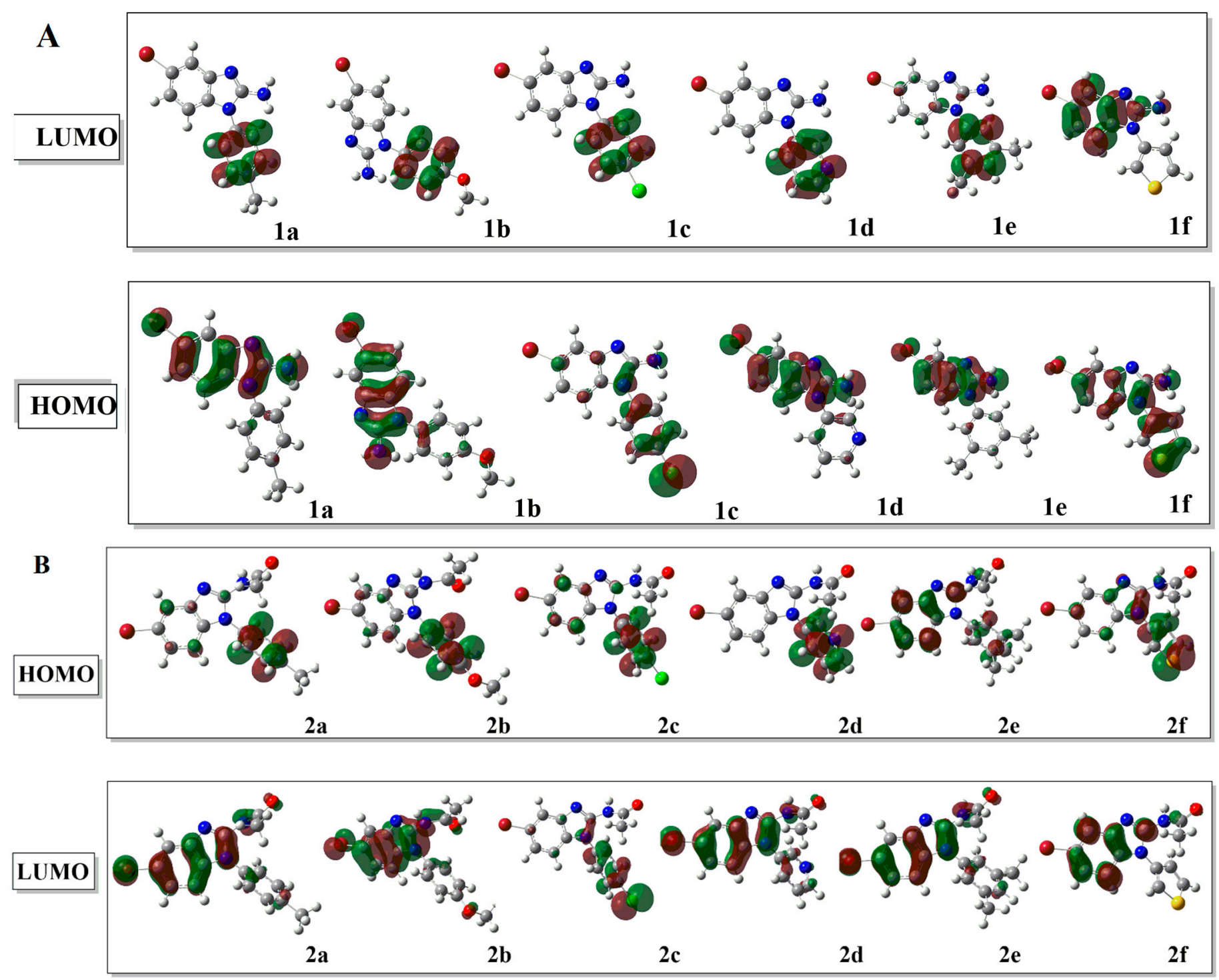

Figure 4. Isodensities of HOMOs and LUMOs of compounds (A) 1a-1f and (B) 2a-2f at cutoff values of 0.05.

\subsubsection{Reactivity Descriptor Parameters}

For further interpretation of the reactivity of compounds (1a-1f and $\mathbf{2 a - 2 f}$ ), some other reactivity descriptor parameters were also analyzed and the results of their analysis are shown in Table 4 . These parameters involve electron affinity $\left(E_{A}\right)$, ionization potential $(I)$, electronic chemical potential $(\mu)$, chemical hardness $(\eta)$, and electrophilicity index $(\omega)$. According to Koopman's theorem, the negative values of HOMOs and LUMOs correspond to ionization potential $(I)$ and electron affinity $\left(E_{A}\right)$, respectively [42-44].

The value of chemical hardness $(\eta)$ is mathematically calculated as follows:

$$
\text { Chemical hardness }(\eta)=\left(\mathrm{E}_{\mathrm{HOMO}}-\mathrm{E}_{\mathrm{LUMO}}\right) / 2
$$

The chemical hardness of $\mathbf{1 a}-\mathbf{2} \mathbf{f}$ compounds is from 2.13 to $2.35 \mathrm{eV}$. The highly unstable and most reactive compound is $\mathbf{1} \mathbf{d}$ based on its small chemical hardness value $(\eta=2.13 \mathrm{eV})$. Compounds $\mathbf{1 a}, \mathbf{1} \mathbf{b}$, and $\mathbf{1 e}$ are stable compounds which are also confirmed from their $\eta$ values of $2.34,2.33$, and $2.35 \mathrm{eV}$, respectively. The chemical hardness of other compounds is between 2.24 and $2.26 \mathrm{eV}$ representing their moderate stability and reactivity. Ionization energy is between 5.78 and $6.02 \mathrm{eV}$ and electron affinity are in the range of $1.10-1.77 \mathrm{eV}$. Looking towards compounds $\mathbf{2 a - 2 f}$, we see that $\mathbf{2 d}$ has lower chemical hardness $(2.39 \mathrm{eV})$, 
and others are noticed as hard compounds; their $\eta$ values range from 2.45 to $2.54 \mathrm{eV}$. The ionization potential and electron affinity values of $\mathbf{2 a - 2} \mathbf{f}$ are more than those of $\mathbf{1 a}-\mathbf{2} \mathbf{f}$ (Table 4).

Table 4. Ionization potential $(I)$, electron affinity $\left(E_{A}\right)$, chemical hardness $(\eta)$, electronic chemical potential $(\mu)$, and electrophilicity index $(\omega)$ of compounds $\mathbf{1 a}-\mathbf{1 f}$ and $\mathbf{2 a - 2 f}$.

\begin{tabular}{cccccc}
\hline Compounds & $\boldsymbol{I}(\mathbf{e V})$ & $\boldsymbol{E}_{\boldsymbol{A}}(\mathbf{e V})$ & $\boldsymbol{\eta}(\mathbf{e V})$ & $\boldsymbol{\mu}(\mathbf{e V})$ & $\boldsymbol{\omega}(\mathbf{e V})$ \\
\hline $\mathbf{1 a}$ & 5.81 & 1.12 & 2.34 & -3.47 & 2.56 \\
$\mathbf{1 b}$ & 5.78 & 1.11 & 2.33 & -3.45 & 2.55 \\
$\mathbf{1 c}$ & 5.99 & 1.50 & 2.24 & -3.75 & 3.12 \\
$\mathbf{1 d}$ & 6.02 & 1.77 & 2.13 & -3.89 & 3.56 \\
$\mathbf{1 e}$ & 5.79 & 1.10 & 2.35 & -3.44 & 2.53 \\
$\mathbf{1 f}$ & 5.91 & 1.39 & 2.26 & -3.65 & 2.94 \\
$\mathbf{2 a}$ & 6.44 & 1.40 & 2.52 & -3.92 & 3.04 \\
$\mathbf{2 b}$ & 6.19 & 1.11 & 2.54 & -3.65 & 2.63 \\
$\mathbf{2}$ & 6.59 & 1.68 & 2.45 & -4.14 & 3.49 \\
$\mathbf{2 d}$ & 6.66 & 1.87 & 2.39 & -4.26 & 3.80 \\
$\mathbf{2 e}$ & 6.42 & 1.39 & 2.52 & -3.90 & 3.03 \\
$\mathbf{2 f}$ & 6.52 & 1.52 & 2.50 & -4.02 & 3.23 \\
\hline
\end{tabular}

Electronic chemical potential $(\mu)$ tells about the charge transfer at their ground state inside the compounds, and it is mathematically represented as follows:

$$
\text { Electronic chemical potential }(\mu)=\left(\mathrm{E}_{\mathrm{HOMO}}+\mathrm{E}_{\mathrm{LUMO}}\right) / 2
$$

where the $\mu$ of compounds $\mathbf{1 a}-\mathbf{1 f}$ is from -3.44 to $-3.89 \mathrm{eV}$. The highest $\mu$ value $(-3.89 \mathrm{eV})$ and lowest $\mu$ value $(-3.44 \mathrm{eV})$ were calculated for $\mathbf{1 d}$ and $\mathbf{1 e}$, respectively. In other series (1a-1f), compound $\mathbf{2 d}$ also has a high value of $\mu(-4.26 \mathrm{eV})$, which signifies that more charge transfer is from an electron donor to acceptor group.

Based on energy, the electrophilicity index $(\omega)$ represents the stability of compounds when an extra charge is transferred from the surrounding [44], and it is mathematically calculated as follows:

$$
\text { Electrophilicity index }(\omega)=\mu^{2} / 2 \eta
$$

For compounds $\mathbf{1 a}-\mathbf{1 f}$, the $\omega$ values range from 3.61 to $4.02 \mathrm{eV}$. The compound $\mathbf{1 d}$ has the highest $\omega$ value of $3.56 \mathrm{eV}$ which indicates that it is less stable for the incoming charge. The presence of electron donor and acceptor groups linked through extended conjugation is the reason for less stability of this compound and enhance its reactivity as incoming charge causes more delocalization of electronic density. In the series of $\mathbf{2 a} \mathbf{a}-\mathbf{2} \mathbf{f}$, the $\omega$ value of $2 \mathrm{~d}$ is $3.80 \mathrm{eV}$ and represents the more charge accepting capability of these compounds. Other compounds have a low $\omega$ value, i.e., up to $2.63 \mathrm{eV}$.

\subsection{Non-Linear Optical (NLO) Properties}

From the start of this century, scientists are following the methods to produce nonlinear optical (NLO) materials because of their potential consumptions in optical data storage, optical communication, optical computing, optical limiting, medical imaging, laser devices, etc. $[45,46]$. To increase the NLO response of the compounds, different strategies are adopted, such as push-pull mechanism [47], metal-organic framework [48], excess electron system $[45,49]$, etc. The organic molecules develop a strong NLO response as the transformation of electrons from donor to acceptor group is responsible for the improved value of $\beta_{\mathrm{o}}$ [50]. Polarizability $\left(\alpha_{0}\right)$ and first hyperpolarizability $\left(\beta_{\mathrm{o}}\right)$ parameters are used to measure the NLO response of respective compounds.

Polarizability $\left(\alpha_{o}\right)$ and hyperpolarizability $\left(\beta_{\mathrm{o}}\right)$ parameters of optical and nonlinear optical properties are studied at different density functionals, i.e., CAM-B3LYP, LC-BLYP, and $\omega B 97 X D$ (vide infra). CAM-B3LYP has a 0.65 fraction of nonlocal exchange at an asymptotic distance and is a highly reliable method for calculating hyperpolarizabilities [36]. Full 
range-separated functionals LC-BLYP [37] and $\omega$ B97XD [38] have the correct 1.00 fraction of nonlocal exchange they are also well-known funtionals in the field of NLO. Almost comparable results are obtained at all selected density functionals where polarizability ranges from 182 to 239 au and hyperpolarizability is between $1.73 \times 10^{-30}$ and $5.63 \times 10^{-30}$ esu for $\mathbf{1 a}-\mathbf{1 f}$ and $\mathbf{2 a - 2} \mathbf{f}$ at LC-BLYP. Polarizability values for all them (1a-1f and $\mathbf{2 a}-\mathbf{2} \mathbf{f})$ is from 188 to 246 au and hyperpolarizability is between $5.31 \times 10^{-30}$ and $1.90 \times 10^{-30}$ esu at $\omega B 97 X D$. Moreover, 188 to 247 au and $2.00 \times 10^{-30}$ to $5.66 \times 10^{-30} \mathrm{esu}$ are the polarizability and the hyperpolarizability ranges for $\mathbf{1 a - 1 f}$ and $\mathbf{2 a - 2} \mathbf{f}$ at CAM-B3LYP (Table 3 and Supplementary Materials Table S1). The highest polarizability (247 au) and hyperpolarizability $\left(5.66 \times 10^{-30} \mathrm{esu}\right)$ are calculated at CAM-B3LYP functional. Therefore, the results of CAM-B3LYP are given in the main manuscript other results are given in supplementary material (Table S1). The short-range intermolecular interaction plays important role in describing optical and nonlinear optical properties of all these compounds due to which the results of CAM-B3LYP are better than the other two functionals.

Polarizability is the distribution of electron density in a system. The compounds having electron-donating and accepting groups at the opposite edge of phenyl rings have a high value of $\alpha_{\mathrm{o}}$ because of positive and negative centers. On the other side, the compounds having equal electronic density distribution due to similar functional groups on the opposite terminal have a low $\alpha_{\mathrm{o}}$ value. The compound 1a has a high value of $\alpha_{\mathrm{o}}$ (220 au) whereas 1e has a low $\alpha_{\mathrm{o}}$ value (182 au). Other compounds have moderate $\alpha_{\mathrm{o}}$ values, from 183 to $208 \mathrm{au}$. The $\alpha_{\mathrm{o}}$ values of compounds $\mathbf{2 a} \mathbf{2} \mathbf{2 f}$ range from 208 to $239 \mathrm{au}$. The $\alpha_{\mathrm{o}}$ value of $\mathbf{2} \mathbf{e}$ is high due to electron-withdrawing and donating groups attached at opposite terminals of the ring.

Benzimidazole ring act as electron-rich species when phenyl ring having different substitution are attached. The shifting of electronic density occurs due to an extended conjugated system between electron-withdrawing and donating groups, the corresponding intersystem charge transfer (ICT) increases the $\beta_{\mathrm{o}}$. The compound $\mathbf{1} \mathbf{b}$ displayed the largest $\beta_{\mathrm{o}}$ value $\left(5.66 \times 10^{-30} \mathrm{esu}\right)$, because of the strong electron-donating group (MeO-) at the para position of the aromatic ring, and on the other side of this molecule, the electron-withdrawing bromine group is attached. According to the push-pull mechanism, shifting of electronic density (ICT) occur under extended conjugation. A $\beta_{\mathrm{o}}$ value of $\left(4.61 \times 10^{-30} \mathrm{esu}\right)$ was observed for compound 1a where a lower electron-donating methyl group is attached to the phenyl ring compared to the methoxy group. The $\beta_{\mathrm{o}}$ values of $\mathbf{1 d}$, 1e, and 1f compounds are $4.40 \times 10^{-30}, 4.00 \times 10^{-30}$, and $4.30 \times 10^{-30} \mathrm{esu}$, respectively. All these compounds have electron-donating property-based substations, i.e., pyridine, di-methylbenzene, and thiazole rings, which enhance $\beta_{\mathrm{o}}$. In compound $1 \mathbf{c}$, chlorine and bromine groups are present on opposite terminals of the compound and result in a lower $\beta_{\mathrm{o}}$ value $\left(3.81 \times 10^{-30} \mathrm{esu}\right)$. Both halogen groups withdraw electronic density towards themselves, and the ICT transfer is low compared to other above-discussed compounds. For compounds $\mathbf{2 a - 2 f}, \beta_{\mathrm{o}}$ values are in a range from $2.00 \times 10^{-30}$ to $3.54 \times 10^{-30}$ esu. Compounds (2a-2f) have a lower $\beta_{\mathrm{o}}$ compared to compounds (1a-2f), but the overall results are similar $\mathbf{1 a}-\mathbf{2} \mathbf{f}$ series. The reason is the acetamide group where resonance occurs between the nitrogen and carbonyl groups, and it also acts as an electron-donating group, although the extent of donation is low. Strong electron-donating methoxy of $\mathbf{2 b}$ $\left(3.54 \times 10^{-30} \mathrm{esu}\right)$, moderate electron-donating pyridine, and thiophene groups of $2 \mathrm{~d}$ $\left(2.40 \times 10^{-30} \mathrm{esu}\right)$ and $2 \mathrm{f}\left(2.37 \times 10^{-30} \mathrm{esu}\right)$ enhance delocalization of the $\pi$ bonding and electron-withdrawing group bromine on the other side accept the electronic density. The shifting of density is more in the case of methoxy group as compared to thiophene and pyridine. The sulfur of thiophene (2f) has the opposite effect due to the electronegativity of sulfur, so its $\beta_{\mathrm{o}}$ is lower than the methoxy group. A low electron-donating group methyl in compounds $2 \mathbf{a}\left(2.02 \times 10^{-30} \mathrm{esu}\right), \mathbf{2 e}\left(2.01 \times 10^{-30} \mathrm{esu}\right)$ has a lower tendency to undergo ICT and have comparatively low $\beta_{\mathrm{o}}$. The lowest $\beta_{\mathrm{o}}$ value is obtained for $2 \mathrm{c}$ due to electron-withdrawing groups' attachment on the opposite side but due to the presence 
of moderately electron-donating group the ICT is more compared to $1 \mathrm{c}$ and a value of $2.00 \times 10^{-30}$ is seen.

We compare the result of $\mathbf{1} \mathbf{b}$ at CAM-B3LYP with already reported compounds from benzimidazole family and their comparative graph is given in Table 5 . The table clearly represents that values of our designed compounds are close to the already reported compounds (salicylidenephenyl)benzimidazole] (Spbzl) at B3LYP, salicylidenephenyl)benzimidazole] ${ }^{*}$ (Spbzl $\left.{ }^{*}\right)$ at CAM-B3LYP and 4-((3-(1H-benzimidazol-2-yl)phenylimino)methyl)-3-hydroxybenzoic acid (Pbzlb) at CAM-B3LYP.) in the gaseous phase at B3LYP and CAM-B3LYP level [51]. The table shows almost similar NLO response of our compounds to already reported on which justifies the better performance of our compounds.

Table 5. Hyperpolarizabilty values of currently reported compound $\mathbf{1 b}$ at CAM-B3LYP, and already reported salicylidenephenyl)benzimidazole] (Spbzl) at B3LYP, salicylidenephenyl)benzimidazole] ${ }^{*}$ $\left(\right.$ Spbzl $\left.^{*}\right)$ at CAM-B3LYP and 4-((3-(1H-benzimidazol-2-yl)phenylimino)methyl)-3-hydroxybenzoic acid (Pbzlb) at CAM-B3LYP.

\begin{tabular}{cc}
\hline Compounds & Hyperpolarizability $\left(\boldsymbol{\beta}_{\mathbf{o}}\right)$ \\
\hline $\mathbf{1 b}$ & $5.66 \times 10^{-30}$ \\
Spbzl & $1.27 \times 10^{-29}$ \\
Spbzl & $8.50 \times 10^{-30}$ \\
Pbzlb & $1.48 \times 10^{-29}$ \\
\hline
\end{tabular}

\subsection{UV-VIS Absorption Analysis}

UV-VIS absorption analysis is performed by using the TD-DFT method to get an insight into electronic excitation that occurs from a lower energy state to a higher energy state [52]. UV-VIS spectra of the parent compound (1) and substituted compounds (1a-2f and 2a-2f) are given in Figure 5. Results of oscillating strength $\left(f_{\mathrm{o}}\right)$, excitation energies $(\Delta \mathrm{E})$, and wavelength $(\lambda)$ of all compounds $(\mathbf{1}, \mathbf{1} \mathbf{-}-\mathbf{2} \mathbf{f}$ and $\mathbf{2 a}-\mathbf{2} \mathbf{f})$ are given in Table 6 The redshift is seen in all substituted compounds (1a-2f) in comparison to the parent compound (1). The pronounced effect is seen for $\mathbf{1 a}$ compound in series of $\mathbf{1 a}-\mathbf{2} \mathbf{f}$ compounds. The electronic excitation takes place from donor-acceptor groups. In compounds where on both sides of the parent skeleton electron-donating and withdrawing groups are attached, this excitation is more prominent. In compound $\mathbf{1 a}$, the electron-withdrawing bromine group (-Br) is attached, while, on the other side, the electron-donating methyl group $\left(-\mathrm{CH}_{3}\right)$ is attached. A prominent redshift of $248 \mathrm{~nm}$ wavelength is observed for it (1a). Based on the electrondonating capability of other groups, the corresponding redshift is observed. The increasing trend of wavelength is as follows: $\mathbf{1 a}(248 \mathrm{~nm})>\mathbf{1 b}(226 \mathrm{~nm})>\mathbf{1 d}(221 \mathrm{~nm})>\mathbf{1 f}(217 \mathrm{~nm})>$ 1e $(213 \mathrm{~nm})>$ 1c $(212 \mathrm{~nm})$.

Table 6. Oscillating strength $\left(f_{\mathrm{o}}\right)$, excitation energies $(\Delta \mathrm{E})$ and wavelength $\left(\lambda_{\max }\right)$ of parent and substituted compounds (1,1a-2f and $\mathbf{2 a - 2 f})$.

\begin{tabular}{cccc}
\hline Compounds & $\boldsymbol{f}_{\mathbf{o}}$ & $\boldsymbol{\Delta E}$ & $\boldsymbol{\lambda}_{\max }$ \\
\hline $\mathbf{1}$ & 0.71 & 5.94 & 209 \\
$\mathbf{1 a}$ & 0.16 & 5.00 & 248 \\
$\mathbf{1 b}$ & 0.32 & 5.49 & 226 \\
$\mathbf{1 c}$ & 0.48 & 5.85 & 212 \\
$\mathbf{1 d}$ & 0.18 & 5.62 & 221 \\
$\mathbf{1 e}$ & 0.65 & 5.82 & 213 \\
$\mathbf{1 f}$ & 0.45 & 5.71 & 217 \\
$\mathbf{2 a}$ & 0.40 & 5.69 & 218 \\
$\mathbf{2 b}$ & 0.14 & 5.56 & 223 \\
$\mathbf{2 c}$ & 0.27 & 5.70 & 218 \\
$\mathbf{2 d}$ & 0.48 & 5.78 & 214 \\
$\mathbf{2 e}$ & 0.37 & 5.74 & 216 \\
$\mathbf{2 f}$ & 0.31 & 5.67 & 219 \\
\hline
\end{tabular}



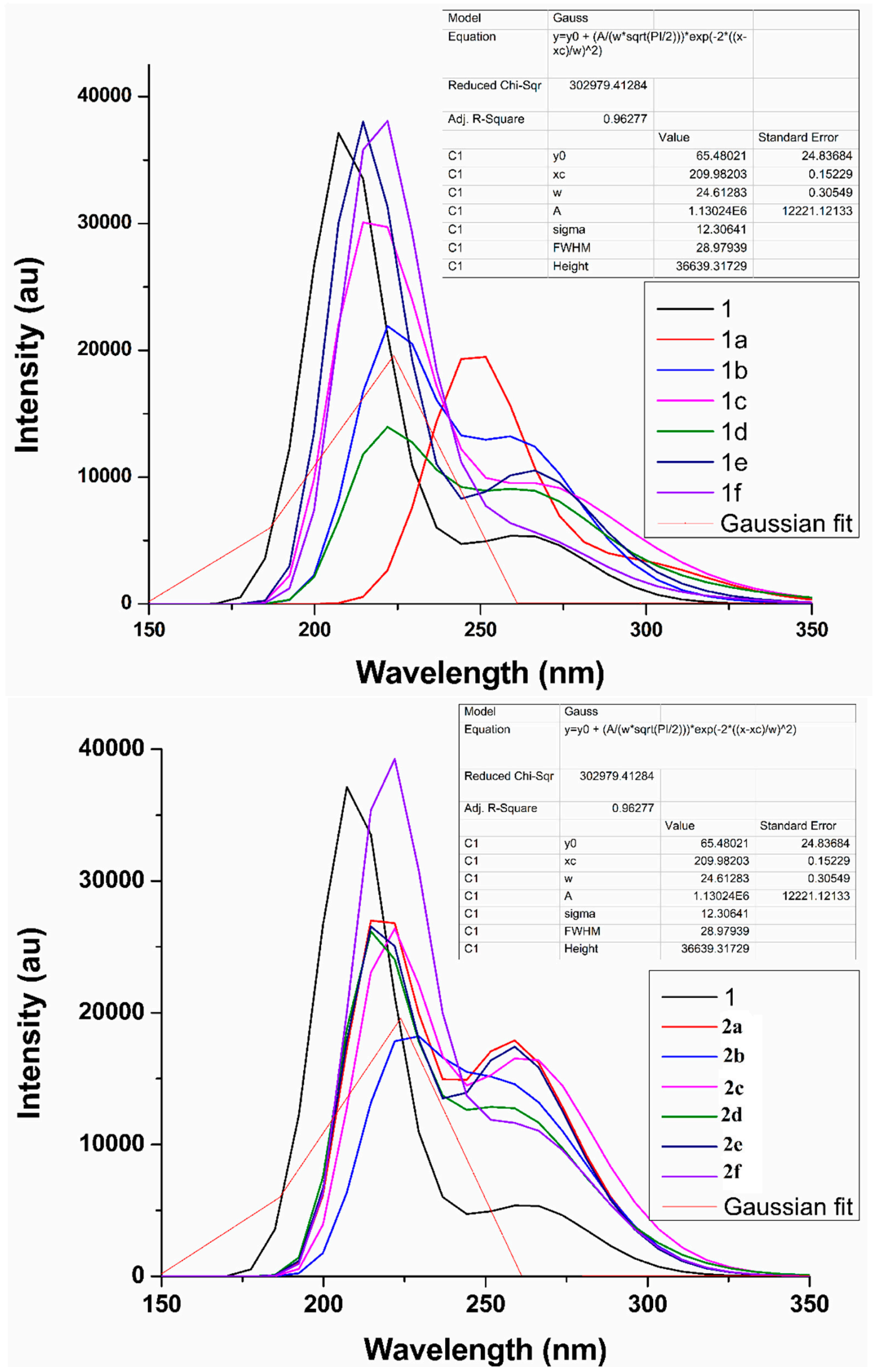

Figure 5. Calculated UV-VIS absorption spectra of parent (1) and substituted compounds (1a-1f (above) and 2a-2f (below)), using GaussView 05 software. The width at half maximum used for the Gaussian broadening is $28.98 \sigma$. 
UV-VIS analysis for $\mathbf{2 a - 2 f}$ series of compounds is also performed where hydrogen is replaced by an amide group (Figure 5). Again, a redshift is seen compared to parent compound 1, which indicates the electronic excitation; the bathochromic shift is seen where peaks move toward a higher wavelength. Maximum wavelength is obtained for compound $\mathbf{2 b}$, where the peak is located at $222 \mathrm{~nm}$. The amide group increases the wavelength of the compounds that have a lower wavelength in the $\mathbf{2 a}-2 \mathbf{f}$ series, because of the presence of electron-withdrawing groups at both opposite terminals (compound 2e). The maximum wavelength for these compounds 2a-2f ranges from 214 to $223 \mathrm{~nm}$. Amide is an electron-withdrawing group, and it facilitates the push-pull mechanism and delocalization of electrons. The observed electronic excitations enable these compounds (1a-1f and $\mathbf{2 a - 2 f})$ as efficient NLO materials usage in a second-harmonic generation. These compounds show transparency below $200 \mathrm{~nm}$, so they can also be used in UV laser technology. Su and co-workers also worked on the single group substitution of benzimidazole; they observed that electron-donating groups decrease the wavelength, whereas the electron-withdrawing group increases the observed wavelength [53]. Their calculated wavelength is lower than our reported maximum wavelength for compounds $\mathbf{1 a}$ and $\mathbf{1 b}$.

\section{Experimental}

All the purchased chemicals (Sigma Aldrich, St. Louis, MO, USA) and solvents were purified before use by distillation, or, for extra purity, some of the solvents were also dried in the lab. All the reactions were completed under and open-air environment. The reaction progress was checked by using a TLC card. Organic solutions were evaporated from the reaction by using a rotatory evaporator (Buchi, R-210, Allschwil, Switzerland) and vacuum pump (Buchi, V-700, Flawil, Switzerland). NMR spectra were calculated in $\mathrm{CDCl}_{3}$ and DMSO- $d_{6}$ by using Bruker ARX 400 and $125 \mathrm{MHz}$ FT-NMR spectrometers (Billercia, MA, USA). Different aryl boronic acid, bases, and solvents were used for the synthesis of required compounds by following specific methods.

\subsection{General Protocol for the Synthesis of Compounds}

3.1.1. General Procedures for the Synthesis of 5-Bromo-1H-benzo[d]imidazol-2-amine Derivatives (1a-1f)

A dry $100 \mathrm{~mL}$ round-bottom flask was loaded with $0.94 \mathrm{mmol}$ of 5-bromo-2aminobenzimidazole (1), $0.94 \mathrm{mmol}$ of $\mathrm{Cu}(\mathrm{OAc})_{2}$, and $8 \mathrm{~mL}$ of methanol. Then the mixture was stirred under an open-air environment for $15 \mathrm{~min}$. After that, $1.88 \mathrm{mmol}$ of base Et3N or TMEDA, $1.128 \mathrm{mmol}$ of aryl boronic acid, and $2 \mathrm{~mL}$ of water were added and stirred again for two hours. The reaction progress was monitored by TLC. After completion, the reaction mixture was filtered and concentrated by rotary evaporated to get residue [29]. The residue was column chromatographed to get the desired product, which was further analyzed by using NMR spectroscopic techniques.

\subsubsection{Synthesis of $N$-(5-Bromo- $1 H$-benzo[ $d]$ imidazol-2-yl) Acetamide (2)}

The mixture of 5-bromo-2-aminobenzimidazole $(0.1 \mathrm{~g}, 0.47 \mathrm{mmol})$ in $5 \mathrm{~mL}$ of acetic anhydride was heated at $40^{\circ} \mathrm{C}$ for $4 \mathrm{~h}$. The precipitates of the reaction mixture were cooled to $0{ }^{\circ} \mathrm{C}$, then filtered off and washed with DCM and water. Finally, they were dried to give the final product with white crystals [28].

3.1.3. General Procedures for the Synthesis of N-(5-Bromo-1H-benzo[d]imidazol-2-yl) Acetamide Derivatives (2a-2f)

A dry $100 \mathrm{~mL}$ round-bottom flask was loaded with $0.39 \mathrm{mmol}$ of $\mathrm{N}$-(5-bromo- $1 \mathrm{H}$ benzo[d]imidazol-2-yl)acetamide, $0.47 \mathrm{mmol}$ of aryl boronic acid, $0.59 \mathrm{mmol}$ of $\mathrm{Cu}(\mathrm{OAc})_{2}$, $0.59 \mathrm{mmol}$ of triethylamine, $100 \mathrm{mg}$ of $4 \AA$ molecular sieves, and then $10 \mathrm{~mL}$ of dry DCM. Then, the reaction mixture was stirred at room temperature, for $36 \mathrm{~h}$; TLC examination was carried out to monitor the reaction completion. Upon completion, the reaction mixture was filtered and washed with ethyl acetate $(5 \mathrm{~mL})$. Then, the solvent was evaporated by rotary evaporation to obtain the residue $[15,30]$. The residue was column chromatographed by 
utilizing a mixture of hexane and ethyl acetate (60/40) to obtain the wanted product with a good \% yield, which was further analyzed by using NMR spectroscopic techniques. The NMR spectra are given in Supplementary Material (Figures S1-S18).

\subsection{Characterization Data}

5-bromo-1-p-tolyl-1H-benzo[d]imidazol-2-amine (1a): ${ }^{1} \mathrm{H}-\mathrm{NMR}\left(400 \mathrm{MHz}, \mathrm{CDCl}_{3}\right): \delta=7.86$ $(\mathrm{d}, J=6.9 \mathrm{~Hz}, 3 \mathrm{H}), 7.18(\mathrm{~d}, J=7.5 \mathrm{~Hz}, 3 \mathrm{H}), 7.12(\mathrm{~d}, J=8.0 \mathrm{~Hz}, 1 \mathrm{H}), 6.98(\mathrm{~s}, 2 \mathrm{H}), 2.34(\mathrm{~s}, 3 \mathrm{H})$. ${ }^{13} \mathrm{C}-\mathrm{NMR}\left(125 \mathrm{MHz}\right.$, DMSO- $\left.d_{6}\right): \delta=158.42,142.54,140.36,138.02,137.53,128.95,128.85$, $128.22,127.79,124.96,119.63,112.46,111.18,21.15$. Anal. Calcd. For $\mathrm{C}_{14} \mathrm{H}_{12} \mathrm{BrN}_{3}$ : C, 55.65; H, 4.00; N, 13.91. Found: C, 55.72; H, 4.09; N, 13.88 .

5-bromo-1-(4-methoxyphenyl)-1H-benzo[d]imidazol-2-amine (1b): ${ }^{1} \mathrm{H}-\mathrm{NMR}(400 \mathrm{MHz}$, $\left.\mathrm{CDCl}_{3}\right): \delta=7.93(\mathrm{~d}, J=7.9 \mathrm{~Hz}, 2 \mathrm{H}), 7.70(\mathrm{~d}, J=29.8 \mathrm{~Hz}, 1 \mathrm{H}), 7.08(\mathrm{~d}, J=7.4 \mathrm{~Hz}, 1 \mathrm{H})$, 6.94-6.91 (m, 3H), $6.82(\mathrm{~s}, 2 \mathrm{H}), 3.80(\mathrm{~s}, 3 \mathrm{H}) .{ }^{13} \mathrm{C}-\mathrm{NMR}\left(125 \mathrm{MHz}, \mathrm{DMSO}-d_{6}\right): \delta=155.58$, 140.21, 140.14, 134.50, 130.67, 124.58, 121.64, 1117.64, 116.91, 113.68, 110.82, 110.77, 109.87, 60.33. Anal. Calcd. For $\mathrm{C}_{14} \mathrm{H}_{12} \mathrm{BrN}_{3} \mathrm{O}: \mathrm{C}, 52.85 ; \mathrm{H}, 3.80 ; \mathrm{N}, 13.21$. Found: $\mathrm{C}, 52.83 ; \mathrm{H}, 3.86$; $\mathrm{N}, 13.25$.

5-bromo-1-(3-chlorophenyl)-1H-benzo[d]imidazol-2-amine (1c): ${ }^{1} \mathrm{H}-\mathrm{NMR}(400 \mathrm{MHz}, \mathrm{CDCl} 3)$ $\delta=7.85(\mathrm{~d}, J=7.9 \mathrm{~Hz}, 3 \mathrm{H}), 7.63(\mathrm{~s}, 1 \mathrm{H}), 7.33(\mathrm{~d}, J=8.2 \mathrm{~Hz}, 4 \mathrm{H}), 7.22(\mathrm{~d}, J=6.8 \mathrm{~Hz}, 1 \mathrm{H})$. ${ }^{13} \mathrm{C}-\mathrm{NMR}(125 \mathrm{MHz}$, DMSO-d6): $\delta=160.87,156.29,150.14,141.45,139.32,139.20,137.30$, 134.46, 121.11, 118.66, 114.38, 112.41, 110.88. Anal. Calcd. For C13H9BrCIN3: C, 48.40; H, $2.81 ; \mathrm{N}, 13.03$. Found: C, 48.48; H, 2.85; N, 13.00 .

5-bromo-1-(pyridin-3-yl)-1H-benzo[d]imidazol-2-amine (1d): ${ }^{1} \mathrm{H}-\mathrm{NMR}\left(400 \mathrm{MHz}, \mathrm{CDCl}_{3}\right)$ $\delta=8.60(\mathrm{~d}, J=4.2 \mathrm{~Hz}, 2 \mathrm{H}), 7.66(\mathrm{t}, J=7.7 \mathrm{~Hz}, 2 \mathrm{H}), 7.41(\mathrm{~s}, 1 \mathrm{H}), 7.14(\mathrm{dt}, J=16.8,8.4 \mathrm{~Hz}, 4 \mathrm{H})$. ${ }^{13} \mathrm{C}-\mathrm{NMR}\left(125 \mathrm{MHz}\right.$, DMSO- $\left.d_{6}\right): \delta=161.80,146.93,136.70,135.23,134.89,134.53,133.57$, $131.78,121.71,119.30,117.42,114.69$. Anal. Calcd. For $\mathrm{C}_{12} \mathrm{H}_{9} \mathrm{BrN}_{4}: \mathrm{C}, 49.85 ; \mathrm{H}, 3.14 ; \mathrm{N}$, 19.38. Found: C, 49.93; H, 3.15; N, 19.33.

5-bromo-1-(3,5-dimethylphenyl)-1H-benzo[d] imidazol-2-amine (1e): ${ }^{1} \mathrm{H}-\mathrm{NMR}(400 \mathrm{MHz}$, $\left.\mathrm{CDCl}_{3}\right) \delta=7.68-7.47(\mathrm{~m}, 5 \mathrm{H}), 7.32(\mathrm{~s}, 1 \mathrm{H}), 7.07(\mathrm{~s}, 2 \mathrm{H}), 2.37(\mathrm{~s}, 6 \mathrm{H}) .{ }^{13} \mathrm{C}-\mathrm{NMR}(125 \mathrm{MHz}$, DMSO- $\left.d_{6}\right): \delta=154.26,151.85,149.37,142.11,136.30,130.94,126.54,120.85,118.15,116.85$, 113.22, 111.00, 27.46. Anal. Calcd. For $\mathrm{C}_{15} \mathrm{H}_{14} \mathrm{BrN}_{3}$ : C, 56.98; H, 4.46; N, 13.29. Found: C, 57.02; H, 4.49; N, 13.24 .

5-bromo-1-(thiophen-3-yl)-1H-benzo[d]imidazol-2-amine (1f): ${ }^{1} \mathrm{H}-\mathrm{NMR}\left(400 \mathrm{MHz}, \mathrm{CDCl}_{3}\right)$ : $\delta=7.82(\mathrm{~s}, 1 \mathrm{H}), 7.49(\mathrm{t}, J=9.7 \mathrm{~Hz}, 2 \mathrm{H}), 7.37-7.32(\mathrm{~m}, 2 \mathrm{H}), 7.12(\mathrm{~d}, J=7.3 \mathrm{~Hz}, 1 \mathrm{H}), 6.98$ $(\mathrm{s}, 2 \mathrm{H}) .{ }^{13} \mathrm{C}-\mathrm{NMR}\left(125 \mathrm{MHz}, \mathrm{DMSO}-d_{6}\right): \delta=154.67,149.45,144.50,129.31,122.00,120.36$, $117.72,116.02,115.76,115.01,111.88$. Anal. Calcd. For $\mathrm{C}_{11} \mathrm{H}_{8} \mathrm{BrN}_{3} \mathrm{~S}: \mathrm{C}, 44.91 ; \mathrm{H}, 2.74 ; \mathrm{N}$, 14.28. Found: C, 44.98; H, 2.76; N, 14.25 .

$\mathrm{N}$-(5-bromo-1H-benzo[d]imidazol-2-yl)acetamide (2): ${ }^{1} \mathrm{H}-\mathrm{NMR}\left(400 \mathrm{MHz}, \mathrm{CDCl}_{3}\right): \delta=7.98$ $(\mathrm{d}, J=2.0 \mathrm{~Hz}, 1 \mathrm{H}), 7.62(\mathrm{dd}, J=9.2,2.8 \mathrm{~Hz}, 2 \mathrm{H}), 6.97(\mathrm{~s}, 1 \mathrm{H}), 5.94(\mathrm{~s}, 1 \mathrm{H}), 2.28(\mathrm{~s}, 3 \mathrm{H})$. ${ }^{13} \mathrm{C}-\mathrm{NMR}\left(125 \mathrm{MHz}, \mathrm{CDCl}_{3}\right): \delta=172.48,147.28,134.47,133.26,122.63,117.39,115.46,112.57$, 23.43. Anal. Calcd. For $\mathrm{C}_{9} \mathrm{H}_{8} \mathrm{BrN}_{3} \mathrm{O}: \mathrm{C}, 42.54 ; \mathrm{H}, 3.17 ; \mathrm{N}, 16.54$. Found: $\mathrm{C}, 42.59 ; \mathrm{H}, 3.20 ; \mathrm{N}$, 16.52 .

N-(5-bromo-1-p-tolyl-1H-benzo[d] imidazol-2-yl)acetamide (2a): ${ }^{1} \mathrm{H}-\mathrm{NMR}\left(400 \mathrm{MHz}, \mathrm{CDCl}_{3}\right)$ : $\delta=8.08(\mathrm{~d}, J=8.1 \mathrm{~Hz}, 1 \mathrm{H}), 7.85(\mathrm{~d}, J=8.1 \mathrm{~Hz}, 1 \mathrm{H}), 7.68(\mathrm{~d}, J=8.1 \mathrm{~Hz}, 2 \mathrm{H}), 7.31(\mathrm{~d}, J=8.1 \mathrm{~Hz}$, 1H), $7.22(\mathrm{~d}, J=8.2 \mathrm{~Hz}, 2 \mathrm{H}), 4.37(\mathrm{~s}, 1 \mathrm{H}), 2.52(\mathrm{~s}, 3 \mathrm{H}), 2.47(\mathrm{~s}, 3 \mathrm{H}) .{ }^{13} \mathrm{C}-\mathrm{NMR}(125 \mathrm{MHz}$, $\left.\mathrm{CDCl}_{3}\right): \delta=172.46,148.04,139.77,137.59,135.30,133.73,130.69,125.23,120.74,118.42$, 115.78, 113.78, 23.91, 20.92. Anal. Calcd. For $\mathrm{C}_{16} \mathrm{H}_{14} \mathrm{BrN}_{3} \mathrm{O}: \mathrm{C}, 55.83 ; \mathrm{H}, 4.10 ; \mathrm{N}, 12.21$. Found: C, 55.91; H, 4.14; N, 12.19 .

N-(5-bromo-1-(4-methoxyphenyl)-1H-benzo[d]imidazol-2-yl)acetamide (2b): ${ }^{1} \mathrm{H}-\mathrm{NMR}(400 \mathrm{MHz}$, $\left.\mathrm{CDCl}_{3}\right): \delta=7.97(\mathrm{~d}, J=1.6 \mathrm{~Hz}, 1 \mathrm{H}), 7.84(\mathrm{~d}, J=8.7 \mathrm{~Hz}, 2 \mathrm{H}), 7.66(\mathrm{~d}, J=8.8 \mathrm{~Hz}, 1 \mathrm{H}), 7.41(\mathrm{dd}$, $J=8.4,1.2 \mathrm{~Hz}, 1 \mathrm{H}), 7.0(\mathrm{~d}, J=8.0 \mathrm{~Hz}, 2 \mathrm{H}), 5.91(\mathrm{~s}, 1 \mathrm{H}), 3.88(\mathrm{~s}, 3 \mathrm{H}), 2.24(\mathrm{~s}, 3 \mathrm{H}) .{ }^{13} \mathrm{C}-\mathrm{NMR}$ $\left(125 \mathrm{MHz}, \mathrm{CDCl}_{3}\right): \delta=171.98,162.78,148.75,138.98,135.39,130.71,128.74,123.64,120.62$, 118.89, 116.32, 113.01, 57.46, 23.86. Anal. Calcd. For $\mathrm{C}_{16} \mathrm{H}_{14} \mathrm{BrN}_{3} \mathrm{O}_{2}: \mathrm{C}, 53.35 ; \mathrm{H}, 3.92 ; \mathrm{N}$, 11.67. Found: C, 53.42; H, 3.90; N, 11.66 . 
N-(5-bromo-1-(3-chlorophenyl)-1H-benzo[d]imidazol-2-yl)acetamide (2c): ${ }^{1} \mathrm{H}-\mathrm{NMR}(400 \mathrm{MHz}$, $\left.\mathrm{CDCl}_{3}\right): \delta=8.04-8.02(\mathrm{~m}, 1 \mathrm{H}), 7.94(\mathrm{~d}, J=1.8 \mathrm{~Hz}, 1 \mathrm{H}), 7.81(\mathrm{~d}, J=1.7 \mathrm{~Hz}, 1 \mathrm{H}), 7.64(\mathrm{~d}$, $J=8.5 \mathrm{~Hz}, 1 \mathrm{H}), 7.47-7.41(\mathrm{~m}, 3 \mathrm{H}), 5.97(\mathrm{~s}, 1 \mathrm{H}), 2.28(\mathrm{~s}, 3 \mathrm{H}) .{ }^{13} \mathrm{C}-\mathrm{NMR}\left(125 \mathrm{MHz}, \mathrm{CDCl}_{3}\right)$ : $\delta=172.67,148.47,138.78,135.56,134.58,132.67,130.77,128.57,126.82,124.04,122.09,120.02$, 117.47, 113.89, 24.01. Anal. Calcd. For $\mathrm{C}_{15} \mathrm{H}_{11} \mathrm{BrClN}_{3} \mathrm{O}: \mathrm{C}, 49.41 ; \mathrm{H}, 3.04 ; \mathrm{N}, 11.52$. Found: C, 49.43; H, 3.09; N, 11.49 .

N-(5-bromo-1-(pyridin-3-yl)-1H-benzo[d]imidazol-2-yl)acetamide (2d): ${ }^{1} \mathrm{H}-\mathrm{NMR}(400 \mathrm{MHz}$, DMSO- $\left.d_{6}\right): \delta=8.17(\mathrm{~d}, J=2.3 \mathrm{~Hz}, 1 \mathrm{H}), 7.96(\mathrm{~d}, J=7.4 \mathrm{~Hz}, 2 \mathrm{H}), 7.80(\mathrm{dd}, J=8.8,2.4 \mathrm{~Hz}, 2 \mathrm{H})$, $7.55(\mathrm{~d}, J=8.8 \mathrm{~Hz}, 2 \mathrm{H}), 4.70(\mathrm{~s}, 1 \mathrm{H}), 2.55(\mathrm{~s}, 3 \mathrm{H}) .{ }^{13} \mathrm{C}-\mathrm{NMR}\left(125 \mathrm{MHz}, \mathrm{CDCl}_{3}\right): \delta=171.94$, 147.92, 145.46, 142.56, 136.84, 134.87, 131.75, 129.99, 125.45, 122.04, 118.52, 117.15, 115.97, 23.67. Anal. Calcd. For $\mathrm{C}_{14} \mathrm{H}_{11} \mathrm{BrN}_{4} \mathrm{O}$ : C, 50.77; H, 3.35; N, 16.92. Found: C, 50.86; H, 3.41; $\mathrm{N}, 16.86$

N-(5-bromo-1-(3,5-dimethylphenyl)-1H-benzo[d]imidazol-2-yl)acetamide (2e): ${ }^{1} \mathrm{H}-\mathrm{NMR}$ $\left(400 \mathrm{MHz}_{\mathrm{CDCl}}\right) \delta=7.67(\mathrm{~s}, 3 \mathrm{H}), 7.34(\mathrm{~s}, 1 \mathrm{H}), 7.11(\mathrm{~d}, J=6.4 \mathrm{~Hz}, 3 \mathrm{H}), 2.34(\mathrm{~s}, 3 \mathrm{H}), 2.32$ $(\mathrm{s}, 6 \mathrm{H}) .{ }^{13} \mathrm{C}-\mathrm{NMR}\left(125 \mathrm{MHz}, \mathrm{DMSO}-d_{6}\right): \delta=172.65,149.19,136.09,134.71,132.25,129.28$, $127.51,126.28,124.61,121.69,117.05,113.96,21.51,17.65$. Anal. Calcd. For $\mathrm{C}_{17} \mathrm{H}_{16} \mathrm{BrN}_{3} \mathrm{O}: \mathrm{C}$, 57.00; H, 4.50; N, 11.73. Found: C, 57.06; H, 4.53; N, 11.70.

$\mathrm{N}$-(5-bromo-1-(thiophen-3-yl)-1H-benzo[d] imidazol-2-yl)acetamide (2f): ${ }^{1} \mathrm{H}-\mathrm{NMR}(400 \mathrm{MHz}$, $\left.\mathrm{CDCl}_{3}\right) \delta=7.98(\mathrm{~d}, J=7.2 \mathrm{~Hz}, 2 \mathrm{H}), 7.84(\mathrm{~s}, 1 \mathrm{H}), 7.63-7.59(\mathrm{~m}, 1 \mathrm{H}), 7.43(\mathrm{~s}, 1 \mathrm{H}), 7.36(\mathrm{~s}$, $1 \mathrm{H}), 4.37(\mathrm{~s}, 1 \mathrm{H}), 2.34(\mathrm{~s}, 3 \mathrm{H}) .{ }^{13} \mathrm{C}-\mathrm{NMR}\left(125 \mathrm{MHz}, \mathrm{DMSO}-d_{6}\right): \delta=172.75,149.97,148.28$, $135.52,131.88,125.49,122.28,121.86,114.90,113.05,111.91,109.59,21.51$. Anal. Calcd. For $\mathrm{C}_{13} \mathrm{H}_{10} \mathrm{BrN}_{3} \mathrm{OS}$ : C, 46.44; H, 3.00; N, 12.50. Found: C, 46.49; H, 2.98; N, 12.56.

\subsection{Computational Details}

All synthesized compounds (1a-1f and $\mathbf{2 a}-\mathbf{2} \mathbf{f})$ were computationally studied by using Gaussian 09 [33] and GaussView 5.0 software [54]. First of all, compounds were optimized at B3LYP functional of DFT. B3LYP functional is widely used for optimization because of fewer chances of errors in the geometrical parameters' description [35,55]. Frequency analyses were done at the same level of theory for further confirmations of these structures as true minima energy structures on potential energy surfaces. An analysis of frontier molecular orbitals (FMOs) was performed, and reactivity descriptor parameters were calculated at B3LYP / 6-31+G(d,p) method. Nonlinear optical (NLO) properties, including polarizabilities and first hyperpolarizability parameters, were measured at CAM-B3LYP [36], LC-BLYP [37], and $\omega B 97 X D[38]$ with a $6-31+G(d, p)[34]$ level.

\section{Conclusions}

Consequently, our investigation concentrated on the cross-coupling of 5-bromo-2aminobenzimidazole and aryl boronic acids under various reaction conditions. The impact of different bases and solvents was observed, and we noted that the reaction is not potent with $\mathrm{Et}_{3} \mathrm{~N}$ and pyridine; however, the reaction products obtained a good yield with TMEDA. Finally, all synthesized derivatives (1a-1f and $\mathbf{2 a - 2 f}$ ) were computationally studied by applying DFT calculations. Frontier molecular orbital (FMO) analysis provides information about the electronic properties and reactivity of compounds. Out of $\mathbf{1 a - 1 f}$, compound $\mathbf{1 d}$, and out of $\mathbf{2 a - 2 f}$, compound $\mathbf{2 d}$ presented the lowest HOMO-LUMO energy gap of 4.25 and $4.79 \mathrm{eV}$, respectively. The isodensity shift was more pronounced for these compounds as compared to others. Reactivity descriptor parameters were also calculated to determine the chemical reactivity relations of all synthesized derivatives. Compounds $\mathbf{1} \mathbf{d}$ and $\mathbf{2} \mathbf{d}$ have the lowest values of chemical hardness (2.13 and $2.39 \mathrm{eV})$, lower electronic chemical potential $(-3.89$ and $-4.26 \mathrm{eV})$, and highest values of electrophilicity index (3.56 and $3.80 \mathrm{eV})$, respectively. Also, Compounds $2 \mathrm{~d}$ has lowest electronic chemical potential $(-4.26 \mathrm{eV})$ among all compounds. The compounds 1a-1f displayed better results for all properties when compared to compounds $\mathbf{2 a}-\mathbf{2} \mathbf{f}$, because the acetamide group shows conjugation between nitrogen and carbonyl groups, where electronic density shifting is low. Moreover, polarizability $\left(\alpha_{0}\right)$ and first hyperpolarizability $\left(\beta_{0}\right)$ parameters were used to measured 
NLO response. Overall, 1a has a high $\alpha$ o value of 228 au, and 2e exhibited the highest value of 247 au due to electron-withdrawing and donating groups attached at opposite terminals of the rings. The highest value of $\beta$ o is shown by $1 \mathrm{~b}\left(5.66 \times 10^{-30} \mathrm{au}\right)$. UV-VIS absorption analysis is performed to understand electronic excitation in the designed compounds. These results suggested the use of these compounds in the field of optics and nonlinear optics.

Supplementary Materials: The following are available online. Figures S1-S18: ${ }^{1} \mathrm{H}-\mathrm{NMR}$ and s ${ }^{13}$ C-NMR pectrum of compound 1a-2f; Table S1: Polarizability and hyperpolarizability of compounds $\mathbf{1 a}-\mathbf{1 f}$ and $\mathbf{2 a - 2 f}$.

Author Contributions: Conceptualization, N.R., U.R. and M.M.; methodology, N.R. and M.M.; formal analysis, G.A.; investigation and data curation G.A. and M.M.; writing draft preparation, G.A. and N.R.; writing-review and editing, N.R., M.M., N.K., G.A. and U.R. All authors have read and agreed to the published version of the manuscript.

Funding: Article Processing Charges (APC) was funded by Research Management Center (RMC), Universiti Putra Malaysia (UPM), Malaysia.

Institutional Review Board Statement: Not applicable.

Informed Consent Statement: Not applicable.

Data Availability Statement: Not applicable.

Acknowledgments: The present data are part of the Ph.D. thesis research work of Mubeen Mumtaz.

Conflicts of Interest: The authors declare no conflict of interest.

Sample Availability: Samples of the compounds are available from the authors.

\section{References}

1. Karaffa, L.S. The Merck Index: An Encyclopedia of Chemicals, Drugs, and Biologicals; RSC Publishing: London, UK, 2013.

2. Nawrocka, W.; Zimecki, M.; Kuznicki, T.; Kowalska, M.W. Immunotropic Properties of 2-Aminobenzimidazole Derivatives in Cultures of Human Peripheral Blood Cells, Part 5. Arch. Pharm. Int. J. Pharm. Med. Chem. 1999, 332, 85-90. [CrossRef]

3. Mor, M.; Bordi, F.; Silva, C.; Rivara, S.; Zuliani, V.; Vacondio, F.; Rivara, M.; Barocelli, E.; Bertoni, S.; Ballabeni, V. Synthesis, biological activity, QSAR and QSPR study of 2-aminobenzimidazole derivatives as potent H3-antagonists. Bioorganic Med. Chem. 2004, 12, 663-674. [CrossRef]

4. de Dios, A.; Shih, C.; de Uralde, B.L.; Sánchez, C.; del Prado, M.; Martín Cabrejas, L.M.; Pleite, S.; Blanco-Urgoiti, J.; Lorite, M.J.; Nevill, C.R. Design of potent and selective 2-aminobenzimidazole-based p38 $\alpha$ MAP kinase inhibitors with excellent in vivo efficacy. J. Med. Chem. 2005, 48, 2270-2273. [CrossRef] [PubMed]

5. Nawrocka, W.; Sztuba, B.; Kowalska, M.W.; Liszkiewicz, H.; Wietrzyk, J.; Nasulewicz, A.; Pełczyńska, M.; Opolski, A. Synthesis and antiproliferative activity in vitro of 2-aminobenzimidazole derivatives. II Farm. 2004, 59, 83-91.

6. Iriepa, I.; Gil-Alberdi, B.; Gálvez, E.; Villasante, F.J.; Bellanato, J.; Carmona, P. Synthesis, structural, conformational and pharmacological study of some carbamates derived from 3-methyl-2, 4-diphenyl-3-azabicyclo [3.3. 1] nonan-9 3 -ol. J. Mol. Struct. 1999, 482, 437-442. [CrossRef]

7. Vigorita, M.; Previtera, T.; Zappalà, C.; Trovato, A.; Monforte, M.; Barbera, R.; Pizzimenti, F. N-trifluoroacetyl derivatives as pharmacological agents. V. Evaluation of antiinflammatory and antimicrobial activities of some N-heterocyclic trifluoroacetamides. Farmaco 1990, 45, 223-235. [PubMed]

8. Hu, Y.; Long, S.; Fu, H.; She, Y.; Xu, Z.; Yoon, J. Revisiting imidazolium receptors for the recognition of anions: Highlighted research during 2010-2019. Chem. Soc. Rev. 2021, 50, 589-618. [CrossRef] [PubMed]

9. Wahe, H.; Asobo, P.F.; Cherkasov, R.A.; Nkengfack, A.E.; Folefoc, G.N.; Fomum, Z.T.; Doepp, D. Heterocycles of biological importance. Part 6 . The formation of novel biologically active pyrimido [1,2-a] benzimid-azoles from electron deficient alkynes and 2-aminobenzimidazoles. Arkivoc 2003, 2003, 170-177. [CrossRef]

10. Nawrocka, W. Syntheses and pharmacological properties of new 2-aminobenzimidazole derivatives. Boll. Chim. Farm. 1996, 135, 18-23. [PubMed]

11. Rossi, R.; Lessi, M.; Manzini, C.; Marianetti, G.; Bellina, F. Achievement of regioselectivity in transition metal-catalyzed direct C-H (hetero) arylation reactions of heteroarenes with one heteroatom through the use of removable protecting/blocking substituents or traceless directing groups. Tetrahedron 2016, 72, 1795-1837. [CrossRef]

12. Maria Thomas, A.; Sujatha, A.; Anilkumar, G. Goldberg reaction: Development, mechanistic insights and applications. Mini Rev. Org. Chem. 2015, 12, 3-23. [CrossRef] 
13. Reddy, K.R.; Kumar, N.S.; Sreedhar, B.; Kantam, M.L. N-Arylation of nitrogen heterocycles with aryl halides and arylboronic acids catalyzed by cellulose supported copper (0). J. Mol. Catal. A Chem. 2006, 252, 136-141. [CrossRef]

14. Guram, A.S.; Buchwald, S.L. Palladium-catalyzed aromatic aminations with in situ generated aminostannanes. J. Am. Chem. Soc. 1994, 116, 7901-7902. [CrossRef]

15. Chan, D.M.; Monaco, K.L.; Wang, R.-P.; Winters, M.P. New N-and O-arylations with phenylboronic acids and cupric acetate. Tetrahedron Lett. 1998, 39, 2933-2936. [CrossRef]

16. Rao, D.N.; Rasheed, S.; Kumar, K.A.; Reddy, A.S.; Das, P. Copper-Catalyzed C-NH2 Arylation of 2-Aminobenzimidazoles and Related C-Amino-NH-azoles. Adv. Synth. Catal. 2016, 358, 2126-2133. [CrossRef]

17. Qiao, J.X.; Lam, P.Y. Recent Advances in Chan-Lam Coupling Reaction: Copper-Promoted C-Heteroatom Bond Cross-Coupling Reactions with Boronic Acids and Derivatives. In Boronic Acids: Preparation and Applications in Organic Synthesis, Medicine and Materials, 1E2, 2nd ed.; John Wiley \& Sons GmbH: Weinheim, Germany, 2011; Volume 1, pp. 315-361.

18. Cramer, C.J.; Bickelhaupt, F. Essentials of computational chemistry. Angew. Chem. Int. Ed. Engl. 2003, 42, 381.

19. Koch, W.; Holthausen, M.C. A Chemist's Guide to Density Functional Theory; John Wiley \& Sons: Hoboken, NJ, USA, 2015.

20. Ledoux, I. New advances in molecular engineering for quadratic nonlinear optics. Synth. Met. 1993, 54, 123-137. [CrossRef]

21. Duo-rong, Y.; Dong, X.; Nan, Z.; Ming-guo, L.; Min-hua, J. Organic nonlinear optical crystal MHBA for compact blue-violet laser. Chin. Phys. Lett. 1996, 13, 841.

22. Muhammad, S.; Xu, H.; Janjua, M.R.S.A.; Su, Z.; Nadeem, M. Quantum chemical study of benzimidazole derivatives to tune the second-order nonlinear optical molecular switching by proton abstraction. PCCP 2010, 12, 4791-4799. [CrossRef]

23. Tayade, R.P.; Sekar, N. Benzimidazole-thiazole based NLOphoric styryl dyes with solid state emission-Synthesis, photophysical, hyperpolarizability and TD-DFT studies. Dye. Pigment. 2016, 128, 111-123. [CrossRef]

24. Thakare, S.S.; Sreenath, M.C.; Chitrambalam, S.; Joe, I.H.; Sekar, N. Non-linear optical study of BODIPY-benzimidazole conjugate by solvatochromic, Z-scan and theoretical methods. Opt. Mater. 2017, 64, 453-460. [CrossRef]

25. Tamer, Ö.; Gözüaçık, F.; Avc1, D.; Atalay, Y. Theoretical analysis on structural, spectroscopic, and electronic properties of some 2-aminobenzimidazole complexes by using PBE1PBE, B3LYP, and HF methods. Opt. Spectrosc. 2014, 116, 12-32. [CrossRef]

26. Muthuraja, A.; Kalainathan, S. A study on growth, optical, mechanical, and NLO properties of 2-Mercaptobenzimidazole, 2-Phenylbenzimidazole and 2-Hydroxy benzimidazole single crystals: A comparative investigation. Mater. Technol. 2017, 32, 335-348. [CrossRef]

27. Zhan, C.-G.; Nichols, J.A.; Dixon, D.A. Ionization potential, electron affinity, electronegativity, hardness, and electron excitation energy: Molecular properties from density functional theory orbital energies. J. Phys. Chem. A 2003, 107, 4184-4195. [CrossRef]

28. Ma, C.; Liu, Z.; Yao, Q. Synthesis and characterization of 5-amino-1,3,6-trinitro-1H-benzo[d]imidazol-2(3H)-one as an energetic material. RSC Adv. 2014, 4, 42215-42219. [CrossRef]

29. Yue, Y.; Zheng, Z.G.; Wu, B.; Xia, C.Q.; Yu, X.Q. Copper-Catalyzed Cross-Coupling Reactions of Nucleobases with Arylboronic Acids: An Efficient Access to N-Arylnucleobases. Eur. J. Org. Chem. 2005, 2005, 5154-5157. [CrossRef]

30. Ikram, H.M.; Rasool, N.; Hashmi, M.A.; Anjum, M.A.; Ali, K.G.; Zubair, M.; Ahmad, G.; Mahmood, T. Density functional theory-supported studies of structural and electronic properties of substituted-phenol derivatives synthesized by efficient O-or C-arylation via Chan Lam or Suzuki cross-coupling reactions. Turk. J. Chem. 2019, 43, 1306-1321. [CrossRef]

31. Inque, S.; Imanaka, Y. Reactions of organozinc coordination compounds II. Reactivity with secondary amines. J. Organomet. Chem. 1972, 35, 1-7. [CrossRef]

32. Collum, D.B. Is N, N, N', N'-tetramethylethylenediamine a good ligand for lithium? Acc. Chem. Res. 1992, 25, 448-454. [CrossRef]

33. Frisch, M.J.; Trucks, G.W.; Schlegel, H.B.; Scuseria, G.E.; Robb, M.A.; Cheeseman, J.R.; Scalmani, G.; Barone, V.; Mennucci, B.; Petersson, G.A.; et al. Gaussian 09, Revision D.01; Gaussian, Inc.: Wallingford, CT, USA, 2009.

34. Ochterski, J.W.; Petersson, G.A.; Montgomery, J.A., Jr. A complete basis set model chemistry. V. Extensions to six or more heavy atoms. J. Chem. Phys. 1996, 104, 2598-2619. [CrossRef]

35. Adamo, C.; Barone, V. Exchange functionals with improved long-range behavior and adiabatic connection methods without adjustable parameters: The $\mathrm{m}$ PW and m PW1PW models. J. Chem. Phys. 1998, 108, 664-675. [CrossRef]

36. Bannwarth, C.; Grimme, S. A simplified time-dependent density functional theory approach for electronic ultraviolet and circular dichroism spectra of very large molecules. Comput. Theor. Chem. 2014, 1040, 45-53. [CrossRef]

37. Iikura, H.; Tsuneda, T.; Yanai, T.; Hirao, K. A long-range correction scheme for generalized-gradient-approximation exchange functionals. J. Chem. Phys. 2001, 115, 3540-3544. [CrossRef]

38. Russo, T.V.; Martin, R.L.; Hay, P.J. Density functional calculations on first-row transition metals. J. Chem. Phys. 1994, 101, 7729-7737. [CrossRef]

39. Yoosefian, M.; Etminan, N. The role of solvent polarity in the electronic properties, stability and reactivity trend of a tryptophane/Pd doped SWCNT novel nanobiosensor from polar protic to non-polar solvents. RSC Adv. 2016, 6, 64818-64825. [CrossRef]

40. Tayade, R.P.; Sekar, N. Novel thiazole based styryl dyes with benzimidazole unit-synthesis, photophysical and TD-DFT studies. J. Fluoresc. 2017, 27, 167-180. [CrossRef]

41. Muhammad, S.; Kumar, S.; Koh, J.; Saravanabhavan, M.; Ayub, K.; Chaudhary, M. Synthesis, characterisation, optical and nonlinear optical properties of thiazole and benzothiazole derivatives: A dual approach. Mol. Simul. 2018, 44, 1191-1199. [CrossRef] 
42. Ayub, K. Are phosphide nano-cages better than nitride nano-cages? A kinetic, thermodynamic and non-linear optical properties study of alkali metal encapsulated X 12 Y 12 nano-cages. J. Mater. Chem. C 2016, 4, 10919-10934. [CrossRef]

43. Hirata, S.; Nooijen, M.; Bartlett, R.J. High-order determinantal equation-of-motion coupled-cluster calculations for ionized and electron-attached states. Chem. Phys. Lett. 2000, 328, 459-468. [CrossRef]

44. Parr, R.G.; Szentpály, L.V.; Liu, S. Electrophilicity index. J. Am. Chem. Soc. 1999, 121, 1922-1924. [CrossRef]

45. Kosar, N.; Mahmood, T.; Ayub, K.; Tabassum, S.; Arshad, M.; Gilani, M.A. Doping superalkali on Zn12O12 nanocage constitutes a superior approach to fabricate stable and high-performance nonlinear optical materials. Opt. Laser Technol. 2019, 120, 105753.

46. Ullah, F.; Kosar, N.; Ayub, K.; Mahmood, T. Superalkalis as a source of diffuse excess electrons in newly designed inorganic electrides with remarkable nonlinear response and deep ultraviolet transparency: A DFT study. Appl. Surf. Sci. 2019, 483, 1118-1128. [CrossRef]

47. Mahmood, N.; Rasool, N.; Ikram, H.M.; Hashmi, M.A.; Mahmood, T.; Zubair, M.; Ahmad, G.; Rizwan, K.; Rashid, T.; Rashid, U. Synthesis of 3, 4-Biaryl-2, 5-Dichlorothiophene through Suzuki Cross-Coupling and Theoretical Exploration of Their Potential Applications as Nonlinear Optical Materials. Symmetry 2018, 10, 766. [CrossRef]

48. Guo, Z.; Cao, R.; Wang, X.; Li, H.; Yuan, W.; Wang, G.; Wu, H.; Li, J. A multifunctional 3D ferroelectric and NLO-active porous metal-organic framework. J. Am. Chem. Soc. 2009, 131, 6894-6895. [CrossRef]

49. Tahir, H.; Kosar, N.; Ayub, K.; Mahmood, T. Outstanding NLO response of thermodynamically stable single and multiple alkaline earth metals doped C20 fullerene. J. Mol. Liq. 2020, 305, 112875. [CrossRef]

50. Lu, S.I. Computational study of static first hyperpolarizability of donor-acceptor substituted (E)-benzaldehyde phenylhydrazone. J. Comput. Chem. 2011, 32, 730-736. [CrossRef]

51. Suman, G.; Bubbly, S.; Gudennavar, S.; Muthu, S.; Roopashree, B.; Gayatri, V.; Gowda, N.N. Structural investigation, spectroscopic and energy level studies of Schiff base: 2-[(3'-N-salicylidenephenyl) benzimidazole] using experimental and DFT methods. J. Mol. Struct. 2017, 1139, 247-254. [CrossRef]

52. Wasim, F.; Kosar, N.; Mahmood, T.; Ayub, K. Sensor applications of polypyrrole for oxynitrogen analytes: A DFT study. J. Mol. Model. 2018, 24, 1-14. [CrossRef] [PubMed]

53. Arif, A.M.; Yousaf, A.; Xu, H.-L.; Su, Z.-M. Spectroscopic behavior, FMO, NLO and substitution effect of 2-(1H-Benzo[d]imidazole2-ylthio)-No-substituted-acetamides: Experimental and theoretical approach. Dye. Pigment. 2019, 171, 107742. [CrossRef]

54. Dennington, R.; Keith, T.; Millam, J. GaussView, Version 5; Semichem Inc.: Shawnee Mission, KS, USA, 2009.

55. Kosar, N.; Mahmood, T.; Ayub, K. Role of dispersion corrected hybrid GGA class in accurately calculating the bond dissociation energy of carbon halogen bond: A benchmark study. J. Mol. Struct. 2017, 1150, 447-458. [CrossRef] 